J. Lake Sci. (湖泊科学) , 2011, 23(4): 591-596

http: //www. jlakes. org. E-mail : jlakes@niglas.ac.cn

(C) 2011 by Journal of Lake Sciences

\title{
三峡水库小江回水区春季初级生产力*
}

\author{
郭劲松 ${ }^{1}$, 李 伟 $^{1}$, 李 哲 $^{1}$, 孙志禹 ${ }^{2}$, 陈永柏 ${ }^{2}$, 龙 曼 ${ }^{1}$, 陈 杰 $^{3}$ \\ $(1$ : 重庆大学城市建设与环境工程学院, 重庆 400045) \\ ( 2 : 中国长江三峡集团公司, 宜昌 443002) \\ (3: 林同棪国际工程咨询 (中国) 有限公司, 重庆 401121)
}

摘 要: 2010 年 $4 、 5$ 月份, 用黑白瓶法对小江回水区春季浮游植物初级生产力进行了原位监测, 并研究了初级生产力的 分布特征及其与光强、叶绿素 $\mathrm{a}$ 浓度 $(C h l . a)$ 、水温、二氧化碳分压 $\left(p \mathrm{CO}_{2}\right)$ 等影响因素的相关关系. 结果表明,4、5 月份小江回水 区的水柱总初级生产力 $(G P P)$ 分别为 $1927.5 、 1325.0 \mathrm{mg} \mathrm{O} /\left(\mathrm{m}^{2} \cdot \mathrm{d}\right)$, 平均值为 $1626.3 \mathrm{mg} \mathrm{O}_{2} /\left(\mathrm{m}^{2} \cdot \mathrm{d}\right)$; 总呼吸作用 $(G R)$ 分别为 $1037.5 、 1062.5 \mathrm{mg} \mathrm{O} /\left(\mathrm{m}^{2} \cdot \mathrm{d}\right)$, 平均值为 $1050.0 \mathrm{mg} \mathrm{O} /\left(\mathrm{m}^{2} \cdot \mathrm{d}\right)$; 总净生产力 $(G N P)$ 分别为 $890.0 、 262.5 \mathrm{mg}$ $\mathrm{O}_{2} /\left(\mathrm{m}^{2} \cdot \mathrm{d}\right)$, 平均值为 $576.3 \mathrm{mg} \mathrm{O} /\left(\mathrm{m}^{2} \cdot \mathrm{d}\right) ; G P P / G R$ 分别为 $1.86 、 1.25$, 均大于 1 , 表明 $4 、 5$ 月份小江属于自养型水体. 各层总生产量 $(P)$ 和生产量与呼吸量的相对值 $(P / R)$ 有相似的垂直分布特征, 最大值出现在表层水中, 然后随水深增加 而减小. 相关分析结果表明, $P$ 同光强 $(I)$ 和 $C h l . a$ 呈显著正相关关系, 建立相应的线性回归模型分别为: $P=0.154 C h l . a$ $-0.278, R^{2}=0.570 ; P=0.001 I-0.013, R^{2}=0.942$.

关键词: 三峡水库; 小江; 浮游植物; 初级生产力

\section{Spring primary productivity in Xiaojiang River backwater area in the Three Gorges Reser- voir}

GUO Jinsong ${ }^{1}$, LI Wei ${ }^{1}$, LI Zhe ${ }^{1}$, SUN Zhiyu ${ }^{2}$, CHEN Yongbo ${ }^{2}$, LONG Man ${ }^{1} \&$ CHEN Jie ${ }^{3}$

(1: Faculty of Urban Construction and Environmental Engineering, Chongqing University, Chongqing 400045, P. R. China)

(2: China Three Gorges Cooperation, Yichang 443002, P. R. China)

(3:T. Y. Lin International Engineering Consulting (China) Co. , Itd. , Chongqing 401121, P. R. China)

Abstract: During April and May in 2010, the primary production in the Xiaojiang River backwater area, Three Gorges Reservoir was measured using the black-white-bottle method. The distribution features and relationships with light intensity, chlorophyll-a concentration ( Chl. a), water temperature and partial pressure of carbon dioxide $\left(p \mathrm{CO}_{2}\right)$ were studied. The results showed that the gross primary productivities $(G P P)$ were $1927.5 \mathrm{mg} \mathrm{O}_{2} /\left(\mathrm{m}^{2} \cdot \mathrm{d}\right)$ and $1325.0 \mathrm{mg} \mathrm{O} /\left(\mathrm{m}^{2} \cdot \mathrm{d}\right)$ in April and May, respectively, the average value was $1626.3 \mathrm{mg} \mathrm{O} /\left(\mathrm{m}^{2} \cdot \mathrm{d}\right)$. The gross respirations $(G R)$ in the two months were $1037.5 \mathrm{mg} \mathrm{O}_{2} /\left(\mathrm{m}^{2} \cdot \mathrm{d}\right)$ and $1062.5 \mathrm{mg} \mathrm{O} / \mathrm{m}^{2} \cdot \mathrm{d}$, respectively, and the average value was $1050.0 \mathrm{mg} \mathrm{O}_{2} /\left(\mathrm{m}^{2} \cdot \mathrm{d}\right)$. The gross net productivities $\left(\right.$ GNP) in the two months were $890.0 \mathrm{mg} \mathrm{O} /\left(\mathrm{m}^{2} \cdot \mathrm{d}\right)$ and $262.5 \mathrm{mg} \mathrm{O} /\left(\mathrm{m}^{2} \cdot \mathrm{d}\right)$, and the average value was $576.3 \mathrm{mg} \mathrm{O}_{2} /$ $\left(\mathrm{m}^{2} \cdot \mathrm{d}\right)$. Ratio of $G P P / G R$ were 1.86 and 1.25. These indexes suggested that the Xiaojiang River was autotrophic in the spring season. Primary productivity $(P)$ in each depth and the ratio of productivity to respiration $(P / R)$ had similar vertical distribution feature, showing that the maximum values occurred near the surface and they decreased with depth. Correlation analysis showed that light intensity $(I)$ and $C h l$. $a$ were significantly positive correlation with the $P$. Equations of the linear regression model $P$ with Chl. $a$ and with $I$ were respectively: $P=0.154 \mathrm{Chl}$. $a-0.278$, with coefficient $R^{2}=0.570$, and $P=0.001 I-0.013$, with coefficient $R^{2}=0.942$.

Keywords: Three Gorges Reservoir; Xiaojiang River; phytoplankton; primary productivity

* 国家自然科学基金项目 (51009155)、国家“973”计划项目(2010CB955904-02)、中国长江三峡集团公司项目 (CT 09-08-03) 和中央高校基本科研业务费科研专项 “研究生科技创新基金” (CDJXS10 211153 ) 联合资助. 2010 10-11 收稿;2010-12-30 收修改稿. 郭劲松, 男,1963 年生, 教授, 博士生导师; E-mail:guo0768@ 126. com. 
初级生产力是指单位面积水域在单位时间内初级生产者生产有机物的能力, 是水生生态系统结构与功 能的基础环节, 对研究水生生态系统及其环境特征具有重要意义 ${ }^{[1]}$. 初级生产者主要由水生植物、浮游植物 (藻类) 和自养细菌等构成, 通常在大型水体中浮游植物对初级生产的贡献最大. 对水域初级生产力及其结 构特征的认识始于 20 世纪初, 发展至今已经可以采用多种手段确定水域生产力水平及其结构特征, 但不同 水域物理背景并不相同, 影响生产力水平及其结构特征的生态过程较为复杂 ${ }^{[2-7]}$, 这仍是当前水域生产力研 究的重要方面.

三峡水库自 2003 年蓄水后, 库区支流回水区呈现浮游植物大量生长、初级生产力水平迅速升高的富营 养化趋势, 春季频繁暴发的水华现象已成为三峡水库备受关注的生态环境问题之一 ${ }^{[8]}$. 目前不少学者对三 峡库区蓄水前后支流的水文水质和藻类种群结构变化进行了调查研究, 并用多样性指数等方法对水体营养 级别进行综合评价, 普遍认为库区营养状态为中-富营养型 ${ }^{[9-12]}$. 水动力条件改变、营养物输人与积累是诱导 支流回水区出现生产力水平升高与水华形成的主要因素 ${ }^{[13-15]}$. 但三峡水库支流水生态系统中生产与消费的 相互关系并不明晰, 水库季节调蓄对支流生态系统的潜在影响仍不清楚, 从水域生产力水平与结构特征的 角度揭示三峡水库支流回水区初级生产力格局, 是进一步认识其水库湖沼学特征的重要环节.

本研究拟通过对小江回水区春季 (2010 年 4-5 月) 初级生产力进行原位观测研究, 分析初级生产力的格 局特征, 并探讨光强、水温、叶绿素 $\mathrm{a}$ 和水体中溶解性 $\mathrm{CO}_{2}$ 等主要环境要素对初级生产力的影响, 以期从初级生产 力角度进一步揭示三峡水库小江回水区的湖沼学特征, 为分析其水生生态结构与功能提供基础资料.

\section{1 材料与方法}

\section{1 研究区域}

小江流域 (图 1 ) 地处四川盆地东南边缘, 大巴山南麓, 介于 $30^{\circ} 49^{\prime}-31^{\circ} 42^{\prime} \mathrm{N}, 107^{\circ} 56^{\prime}-108^{\circ} 54^{\prime} \mathrm{E}$ 之间, 流域面积 $5172.5 \mathrm{~km}^{2}$, 干流全长 $182 \mathrm{~km}$, 河口距三峡大坝约 $250 \mathrm{~km}$, 是三峡水库中段较大的次级流域之一.三峡 水库蓄水至 $156 \mathrm{~m}$ 后, 小江回水区延伸至开县渠口镇境内, 长度接近 $60 \mathrm{~km}$. 考虑回水区末端受 $145-156 \mathrm{~m}$ 水位 涨落的影响, 本研究选择 $145 \mathrm{~m}$ 以下的永久回水区, 即云阳县渠马至小江河口的河段作为研究区域 (图 2).

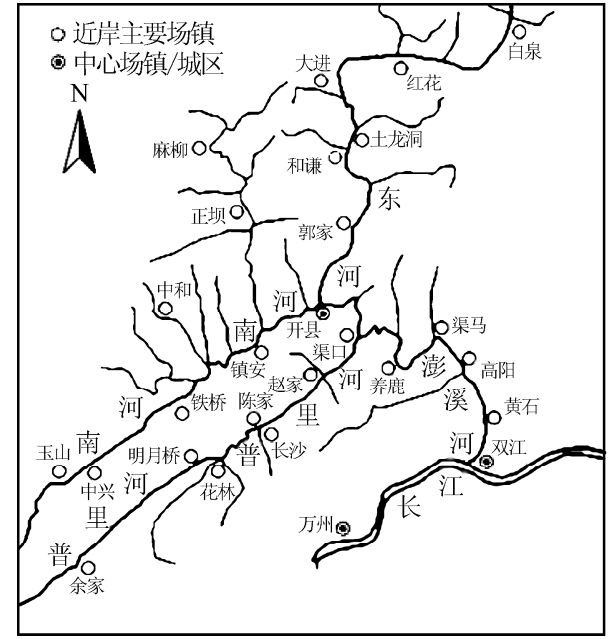

图 1 小江流域水系

Fig. 1 Drainage system of Xiaojiang watershed

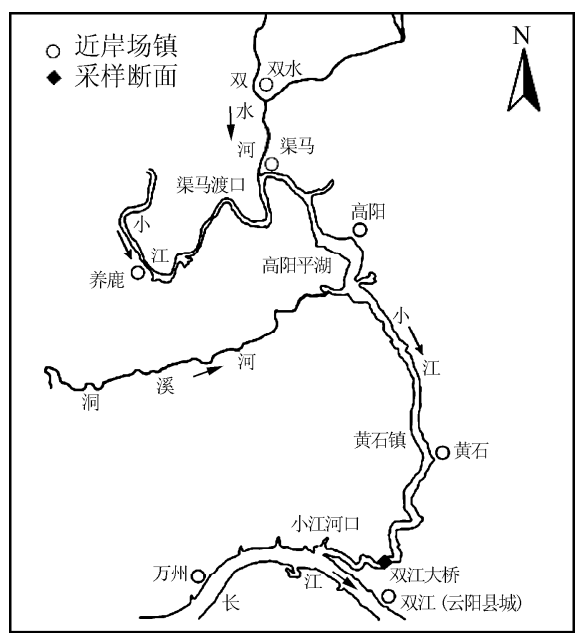

图 2 渠马-小江河口段回水区 和采样点示意图

Fig. 2 Map of backwater area and sampling spot

\section{2 采样方案与数据处理分析方法}

初级生产力的测量最初由 Garder 等在 1927 年提出溶解氧法, 后来 Steemann 在 1952 年提出了 ${ }^{14} \mathrm{C}$ 法, 1987 年 Bender 和 Grande 又提出了 ${ }^{18} \mathrm{O}$ 法, 现在也有人提出用光学方法检测水体初级生产力 ${ }^{[16-19]}$. 但目前普 
遍使用的仍然是前两种方法. 溶解氧法也称为黑白瓶测氧法, 它是根据水中初级生产者光合作用释放氧气的 生物化学原理,将装有水样的黑、白瓶置于不同水层中,测定单位时间内溶解氧含量的变化,借以计算初级生 产力的一种方法. 此法较为简单易行,适用于湖泊、水库、池塘等静水水体以及水流缓和的河流水域.

本研究综合前述的研究成果, 以 Garder 等的溶氧法为基础, 采用 YSI ${ }^{\circledR}$ ProODO 光学溶解氧测定仪测定 黑白瓶内溶解氧. 该方法具有不受流速限制、无流速或摚拌依赖性以及无需预热时间等优点,但在测试过程 中需注意快速测量, 且测量初始溶解氧时要避免瓶内留有气泡.

本研究采样断面布设于小江回水区双江大桥河道深弘线处 $\left(30^{\circ} 56^{\prime} 51.1^{\prime \prime} \mathrm{N}, 108^{\circ} 41^{\prime} 37.5^{\prime \prime} \mathrm{E}\right)$, 于 2010 年 4-5 月水华高发期采用黑白瓶法每月进行 1 次的初级生产力测定,黑白瓶容积为 $350 \mathrm{ml}$. 初级生产力的测试 按 $0 、 0.5 、 1 、 2 、 3 、 5 、 8 、 10 \mathrm{~m}$ 的深度分层进行挂瓶, 次日起瓶, 并分别用溶氧仪测量溶解氧含量. 根据 24 小时 挂瓶前后黑白瓶内溶解氧变化, 可以计算各水层的总生产量 $(P)$ 、净生产量 $(N P)$ 和呼吸作用量 $(R)$, 其计算 方法如下: $P=$ 挂瓶后白瓶溶解氧 - 挂瓶后黑瓶溶解氧; $N P=$ 挂瓶后白瓶溶解氧量 - 初始溶解氧量; $R=$ 初 始溶解氧量 - 挂瓶后黑瓶溶解氧量, 其中 $P 、 N P 、 R$ 单位为 $\mathrm{mg} \mathrm{O}_{2} / \mathrm{L}$. 采用算术平均值累计法计算水柱日生产 力值 $(G P P)$ 和总呼吸作用量 $(G R)$. 以 $G P P$ 为例, 计算公式为:

$$
G P P=\sum_{i=1}^{n-1} \frac{P_{i}+P_{i+1}}{2}\left(D_{i+1}-D_{i}\right)
$$

式中, $P_{i}$ 为第 $i$ 层的总生产量, $D_{i}$ 为第 $i$ 层的深度, $n$ 为取样层次数 $(1 \leqslant i \leqslant n-1), G P P$ 单位为 $\mathrm{mg} \mathrm{O}_{2} /\left(\mathrm{m}^{2} \cdot \mathrm{d}\right)$. 总净生产力值 $(G N P)$ 可由 $G P P$ 和 $G R$ 计算得到 $(G N P=G P P-G R)$. 现场其他测试指标包括水温、光强、二氧 化碳分压 $\left(p \mathrm{CO}_{2}\right)$ 、溶解氧等, 其中光强采用美国 LI-COR 公司生产的 LI-192SA 水下光量子仪测得, 各层水温 和溶解氧用 $\mathrm{YSI}^{\circledR} \mathrm{ProODO}$ 溶氧仪测量, $p \mathrm{CO}_{2}$ 根据 $\mathrm{pH} 、 \mathrm{HCO}_{3}^{-}$及 $K_{\mathrm{h}}$ 进行换算, 并用水温校正 ${ }^{[20]}$. 叶绿素 a (Chl. a ) 用 Whatman ${ }^{\circledR} \mathrm{GF} / \mathrm{C}$ 膜滤后以 $90 \%$ 丙酮溶液萃取, 并采用分光光度法测定其浓度 ${ }^{[21]}$. 所有数据使用 SPSS 进行统计分析.

\section{2 结果与讨论}

\section{1 小江春季初级生产力的特征}

2010 年春季 4、5 月份小江回水区双江断面的 GPP 分别为 1927.5、1325. $0 \mathrm{mg} \mathrm{O}_{2} /\left(\mathrm{m}^{2} \cdot \mathrm{d}\right)$, 平均值为 $1626.3 \mathrm{mg} \mathrm{O}_{2} /\left(\mathrm{m}^{2} \cdot \mathrm{d}\right)$. $G R$ 分别为 $1037.5 、 1062.5 \mathrm{mg} \mathrm{O}_{2} /\left(\mathrm{m}^{2} \cdot \mathrm{d}\right)$, 平均值为 $1050.0 \mathrm{mg} \mathrm{O}_{2} /\left(\mathrm{m}^{2} \cdot \mathrm{d}\right)$; $G N P$ 分别为 $890.0 、 262.5 \mathrm{mg} \mathrm{O}_{2} /\left(\mathrm{m}^{2} \cdot \mathrm{d}\right)$, 平均值为 $576.3 \mathrm{mg} \mathrm{O} /\left(\mathrm{m}^{2} \cdot \mathrm{d}\right)$. 三峡库区另一支流香溪河在 2005 年 春季的 $G P P$ 约为 $5996.0 \mathrm{mg} \mathrm{O} /\left(\mathrm{m}^{2} \cdot \mathrm{d}\right)$; 纬度接近的大型浅水湖泊太湖在 1998 年春季 $G P P$ 约为 $3005.9 \mathrm{mg}$ $\mathrm{O}_{2} /\left(\mathrm{m}^{2} \cdot \mathrm{d}\right)$, 对比可见春季小江回水区初级生产力水平相对偏低 ${ }^{[22-23]}$.

研究期间小江回水区双江断面水深 $0-10 \mathrm{~m}$ 各层总生产量存在明显的垂直分布规律. $P$ 最高值出现在表 层, 然后随水深呈类似于指数规律减小; 总生产量主要集中在 $3 \mathrm{~m}$ 以上水层中, 到 $3 \mathrm{~m}$ 水深以下初级生产力变化平 缓, 至真光层深度 $(7-8 \mathrm{~m}$ ) 处初级生产力接近于零. 各层 $R$ 相对较小, 基本在 $0-0.2 \mathrm{mg} \mathrm{O} / \mathrm{L}$ 范围内变化(图 3).
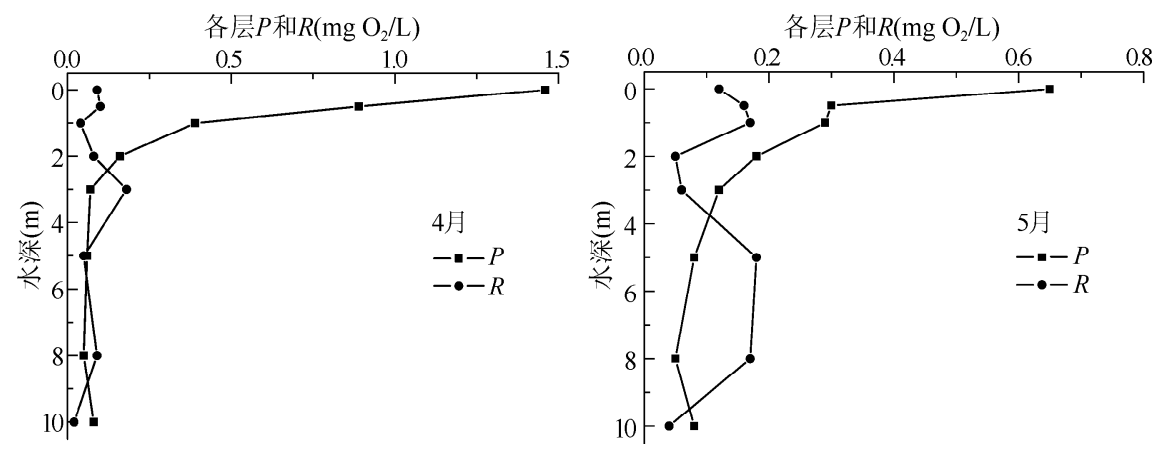

图 $3 P$ 和 $R$ 的垂直分布

Fig. 3 The vertical distribution of $P$ and $R$ 
生产量与呼吸量的相对值 $(P / R)$ 是反映水生生态系统生产力结构的重要指标. 通常在湖泊系统中, $P / R>1$ 表明生态系统以自养过程为主导, 而 $P / R<1$ 则表明以异养生产为主. 一般在贫营养和中营养湖泊

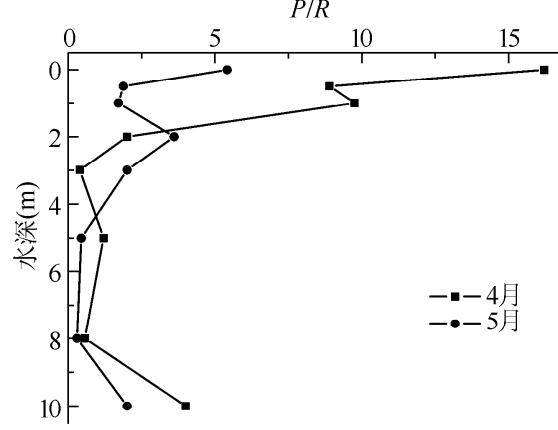

图 $4 P / R$ 垂直分布

Fig. 4 The vertical distribution of $P / R$ 中 $P / R<1$, 在富营养湖泊中 $P / R>1^{[24]}$. 河流系统生产、消费 特征同湖泊存在差异, Grace 等认为, 河流生态系统中 $\mathrm{P} / \mathrm{R}>1$ 为自养型的河流; 而 $P / R<0.5$ 的河流属于异养型河流; 当 $0.5<P / R<1$ 时, 碳源既有外部输人的也有内部产生的, 河流 生态系统介于自养型和异养型之间. 但也有研究将 $P / R=$ 0.75 作为自养型和异养型河流的分界点 ${ }^{[25-27]}$.

本研究中, 小江回水区 $4 、 5$ 月水柱日生产量与总呼吸量 的比值 $(G P P / G R)$ 分别为 1.86 和 1.25 , 均大于 1 , 说明春季该 水域总体呈现自养型特征. 对各水层 $P / R$ 比值的垂直变化分 析可以看出, 垂向上 $P / R$ 总体趋势同 $P$ 的垂向分布特点相 似, 最大值在表层附近出现, $3 \mathrm{~m}$ 以下水层 $P / R$ 基本保持稳定, 但在 $8-10 \mathrm{~m}$ 两指标均出现升高的趋势 (图 4).

\section{2 初级生产力同主要环境因素的相互关系}

光强、温度 $(T) 、 C h l . a 、 p \mathrm{CO}_{2}$ 是同初级生产力密切相关的环境指标, 研究它们同初级生产力的相互关系 有助于认识该时期小江回水区水生生态系统的结构与功能特征. 研究期间, 小江回水区光强、T、Chl. $a$ 和 $p \mathrm{CO}_{2}$ 的垂直分布特征见图 5.
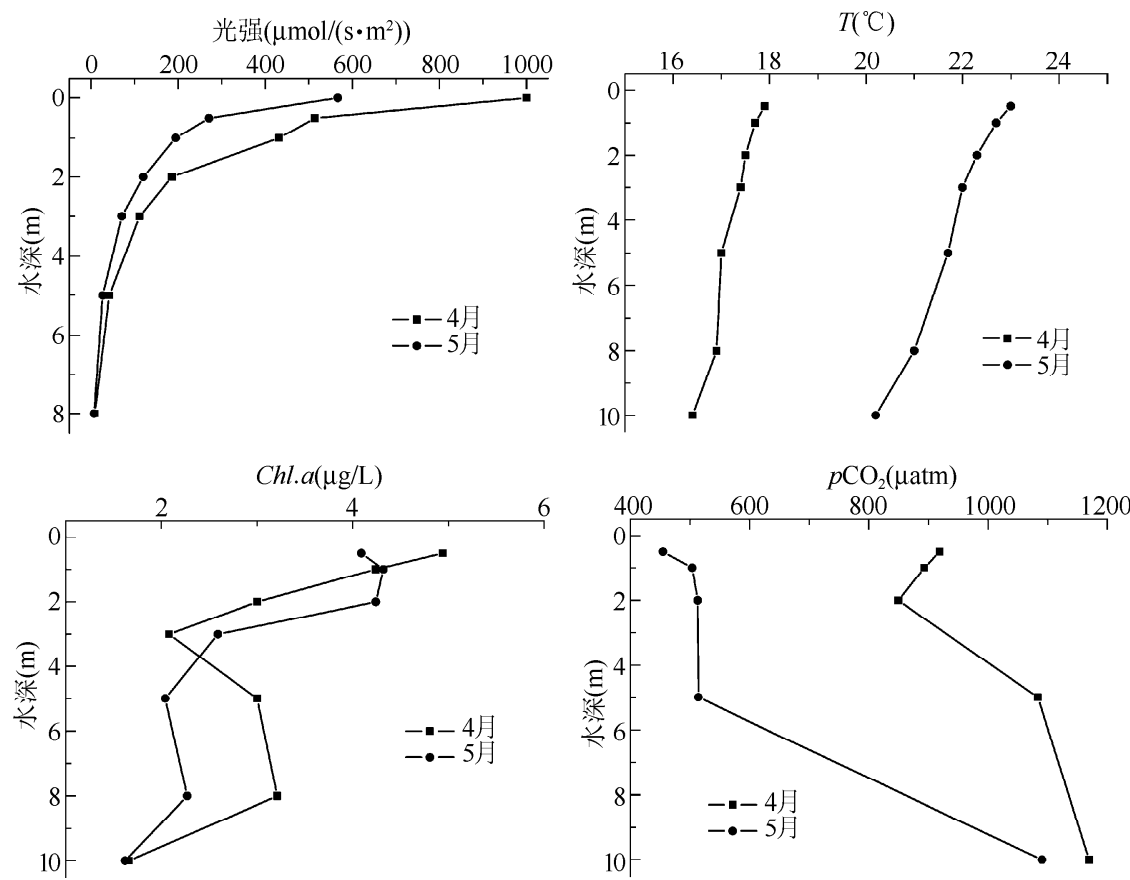

图 5 光强、T、Chl. $a$ 和 $p \mathrm{CO}_{2}$ 垂直分布

Fig. 5 The vertical distribution of light intensity $T 、 C h l$. $a$ and $p \mathrm{CO}_{2}$

本研究选择 Spearman 相关性分析方法建立 2 次采样期间各水层 $P 、 R 、 N P$ 以及 $P / R$ 同上述环境指标的 相互关系,分析结果见表 1. 
表 1 初级生产力与环境指标的 Spearman 相关性矩阵

Tab. 1 Matrix of the correlation coefficients among primary productivity and each environmental indexes

\begin{tabular}{ccccccccc}
\hline & $P$ & $R$ & $N P$ & $P / R$ & 光强 & Chl. $a$ & 水温 & $p \mathrm{CO}_{2}$ \\
\hline$P$ & 1.000 & & & & & & & \\
$R$ & - & 1.000 & & & & & & \\
$N P$ & $0.959^{* * *}$ & - & 1.000 & & & & & \\
$P / R$ & $0.813^{* *}$ & $-0.551^{*}$ & $0.884^{* *}$ & 1.000 & & & & \\
光强 & $0.968^{* *}$ & - & $0.934^{* *}$ & $0.849^{* *}$ & 1.000 & & & \\
$C h l . a$ & $0.651^{*}$ & - & $0.721^{* *}$ & - & $0.737^{* *}$ & 1.000 & & \\
水温 & - & - & - & - & - & - & 1.000 & \\
$p \mathrm{CO}_{2}$ & - & - & - & - & - & - & $-0.830^{* *}$ & 1.000 \\
\hline
\end{tabular}

** 表示显著性水平为 $0.01 ; *$ 表示显著性水平为 $0.05 ; “ 一 ”$ 表示无显著相关性.

研究发现, Chl. $a$ 和光强同 $P 、 N P$ 均呈显著正相关,而水温和 $p \mathrm{CO}_{2}$ 的垂向分布与 $P 、 N P$ 的相关关系并不 显著; $P / R$ 同 $P$ 和光强呈显著正相关,同 $R$ 呈显著负相关,而同 $C h l . a$ 的相关性并不显著; 另外,在上述 4 个 环境要素中, Chl. $a$ 同光强呈显著正相关关系, $p \mathrm{CO}_{2}$ 则同水温呈显著负相关. 根据上述相关性分析结果, 本 研究建立了研究期间 $C h l . a$ 、光强 $(I)$ 同各层总生产量 $P$ 的线性回归模型, 分别为:

$$
\begin{gathered}
P=0.154 \text { Chl. } a-0.278, R^{2}=0.570 \\
P=0.001 I-0.013, R^{2}=0.942
\end{gathered}
$$

同香溪河春季的生产力水平调查结果 ${ }^{[22]}$ 相比, 小江回水区生产力水平较香溪河低. 由于文献 $[22]$ 的数 据采集时期为春季 $139 \mathrm{~m}$ 蓄水状态, 本研究采样时间的水库运行状态为 $150-155 \mathrm{~m}$, 水文水动力条件有一定 差别, 同期香溪河已经发生了明显的水华现象,而采样期间采样点处水华还没大面积出现. 这些因素均在很 大程度上影响了水体生产力水平. 另一方面, 本研究的相关性分析结果表明生产力水平与 $P / R$ 比值同光强 存在显著的相关关系, 在香溪河的研究中也有类似的现象, 这进一步表明了在中-富营养水体中初级生产力 水平可能受控于光照强度.

\section{3 结论}

2010 年三峡小江回水区春季水华高发期水体总体上以自养型为主,对碳的生产显著强于对碳的消费, 浮游植物的光合生产可能是小江回水区碳生产的主要过程;而呼吸作用的宏观表象并不强烈. 光合生产主 要集中分布于 $0-3 \mathrm{~m}$ 水层范围内, 表层的光合生产过程较为剧烈, 但在 $3 \mathrm{~m}$ 以下水层中光合生产强度稳定地 保持在相对较低的水平. 研究期间并未出现显著的水温分层现象, 水温的垂直变化并未对光合生产的垂直 分布产生较大影响, 而光照强度的改变影响更为显著. 由于研究期间呼吸作用分层特征并不明显, 且同主要 环境要素的关系亦较为模糊,故本研究尚难以进一步对细菌降解能力特征进行更深人分析.

\section{4 参考文献}

[ 1 ] Odum HT. Primary production in flowing waters. Limnol \& Oceanogr, 1956, 1(2) : 102-117.

[2] 高 爽,李正炎. 北、黄海夏、冬季叶绿素和初级生产力的空间分布和季节变化特征. 中国海洋大学学报,2009,39 (4):604-610.

[ 3 ] 宁修仁, 刘子琳, 蔡昱明. 我国海洋初级生产力研究二十年. 东海海洋,2000,18(3):13-20.

[ 4 ] 张运林, 冯 胜,马荣华等. 太湖秋季真光层深度空间分布及浮游植物初级生产力的估算. 湖泊科学, 2008,20(3): 380-388.

[ 5 ] Cadée GC, Hegeman J. Primary production of phytoplankton in the Dutch Wadden Sea. Neth J Sea Res, 1974, 8(2-3): 240-259. 
[ 6 ] Arrigo KR, Worthen D, Schnell A et al. Primary production in Southern Ocean waters. J Geophys Res, 1998, 103 (C8) : 15587-15600.

[ 7 ] 杨顶田,陈伟民,陈宇炜等. 太湖梅梁湾水体中初级生产力的光学检测. 湖泊科学,2002,14(4):363-368.

[8] 蔡庆华,胡征宇.三峡水库富营养化问题与对策研究. 水生生物学报,2006,30(1):7-11.

[9] 况琪军, 毕永红, 周广杰等. 三峡水库蓄水前后浮游植物调查及水环境初步分析. 水生生物学报, 2005,29(4): 353-358.

[10］况琪军,胡征宇, 周广杰等. 香溪河流域浮游植物调查与水质评价. 武汉植物学研究,2004,22(6):507-513.

[11] 杨 健, 张 否, 王 娟等. 三峡水库澎溪河回水区藻类种群分布及评价. 西南大学学报 (自然科学版), 2010,32 (5) $: 88-94$.

[12] 李 哲, 郭劲松, 方 芳等. 三峡小江回水区蓝藻季节变化及其与主要环境因素的相互关系. 环境科学, 2010,31 (2) :301-309.

[13] 张 晟, 李崇明,付永川等. 三峡水库成库后支流库湾营养状态及营养盐输出. 环境科学, 2008, 29(1):7-12.

[14] 李 哲,方 芳,郭劲松等.三峡小江回水区段 2007 年春季水华与营养盐特征. 湖泊科学,2009,21(1):36-44.

[15] 方 芳, 李 哲, 田 光. 三峡小江回水区磷素赋存形态季节变化特征及其来源分析. 环境科学, 2009,30(12): 3488-3493.

[16] Michael JB, Paul GF. Photosynthetic rates derived from satellite-based chlorophyll concentration. Limnol \& Oceanogr, $1997, \mathbf{4 2}(1): 1-20$.

[17] Garder T, Gran HH. Investigations of the production of plankton in the Oslo Fjord. Rap Proc Verb Cons Prem Int Explor Mer, $1927,42: 1-48$.

[18] Steemann NE. The use of radio-active carbon $\left({ }^{14} \mathrm{C}\right)$ for measuring organic production in the sea. J Cons Int Explor Mer, $1952, \mathbf{1 8}(2): 117-140$.

[19] Bender ML, Grande KD. Production, respiration and the isotope geochemistry of $\mathrm{O}_{2}$ in the upper water column. Global Biogeochem Cy, 1987, 1(1) : 49-59.

[20 ] Cole JJ, Caraco NF, Kling GW et al. Carbon dioxide supersaturation in the surface waters of lakes. Science, 1994, 265: 1568-1570.

[21］国家环境保护总局. 水和废水监测分析方法(第四版). 北京: 中国环境科学出版社,2002:670-671.

[22] 邵晓阳, 徐耀阳, 韩新芹. 香溪河官庄坪库湾叶绿素 $\mathrm{a}$ 及初级生产力的分布特征. 水生生物学报, 2006,30 (1): 96-100.

[23] 张运林,秦伯强,陈伟民等. 太湖梅梁湾春季浮游植物初级生产力. 湖泊科学, 2005,17(1) :81-86.

[24] Giorgio PA, Peters RH. The balance between phytoplankton production and plankton respiration in lakes. Can J Fish Aquat Sci, $1993, \mathbf{5 0}:$ 282-289.

[25] Grace MR, Imberger SJ. Stream metabolism: performing and interpreting measurements (technical manual). Australia: Monash University, 2006: 24-27.

[26] Vannote RL, Minshall GW, Cummins KW et al. The river continuum Concept. Can J Fish Aquat Sci, 1980, 37 : 130-137.

[27] 张运林, 秦伯强, 胡维平等. 湖典型湖区真光层深度的时空变化及其生态意义. 中国科学 ( D 辑: 地球科学), 2006, 36 (3) :287-296. 